\title{
Desempenho e características de carcaça de cordeiros Santa Inês e suas cruzas com Dorper terminados em confinamento
}

\author{
Performance and carcass traits of Santa Ines pure lambs and crosses with Dorper \\ finished in feedlot
}

\author{
CARTAXO, Felipe Queiroga ${ }^{1}$; SOUSA, Wandrick Hauss de ${ }^{2}$; CEZAR, Marcílio \\ Fontes $^{3}$; CUNHA, Maria das Graças Gomes ${ }^{2}$; MENEZES, Lenice Mendonça de ${ }^{2}$; \\ RAMOS, João Paulo de Farias ${ }^{2 *}$; GOMES, Josimar Torres ${ }^{2}$; VIANA, Jefferson Alves ${ }^{2}$
}

1Universidade Estadual da Paraíba, Catolé do Rocha, Paraíba, Brasil.
${ }^{2}$ Empresa Estadual de Pesquisa Agropecuária da Paraíba, Soledade, Paraíba, Brasil.
${ }^{3}$ Universidade Federal de Campina Grande, Patos, Paraíba, Brasil.
${ }^{*}$ Endereço para correspondência: felipeqcartaxo@yahoo.com.br

\section{RESUMO}

Objetivou-se avaliar o desempenho e características de cordeiros Santa Inês e suas cruzas desmamados aos 75 dias de vida e terminados em confinamento. Foram utilizados 30 cordeiros não castrados, 10 Santa Inês, 10 $1 / 2$ Dorper x $1 / 2$ Santa Inês e 10 3/4Dorper x 1/4Santa Inês, com idade e peso vivo médio no início do experimento de 82 dias e $19,40 \mathrm{~kg}$, respectivamente. Foi utilizada dieta única contendo $169,0 \mathrm{~g} / \mathrm{kg}$ de proteína bruta e 2,80 $\mathrm{Mcal} / \mathrm{kg}$ MS. Não houve efeito do genótipo sobre o desempenho dos cordeiros, exceto para escore corporal final, em que os mestiços Dorper alcançaram os maiores escores. As carcaças dos cordeiros $1 / 2$ Dorper x $1 / 2$ Santa Inês e $3 / 4$ Dorper $x$ $1 / 4$ Santa Inês apresentaram maior largura da garupa, área de olho de lombo e percentual de lombo do que as carcaças dos cordeiros Santa Inês. As carcaças dos cordeiros 3/4Dorper x $1 / 4$ Santa Inês alcançaram maior largura do tórax e do anterior quando comparadas com as carcaças dos cordeiros Santa Inês, tendo obtido também melhor conformação e acabamento de carcaça quando comparadas com as carcaças dos demais genótipos. Entretanto, as carcaças dos cordeiros Santa Inês e 1/2Dorper x 1/2Santa Inês apresentaram maior percentual de pescoço em relação às carcaças dos cordeiros 3/4Dorper x 1/4 Santa Inês.

Palavras-chave: acabamento, consumo de matéria seca, cruzamento, ganho de peso, genótipo

\section{SUMMARY}

This study evaluated the performance and carcass traits of Santa Ines sheep and crosses weaned at 75 days old and finished in feedlot. Thirty uncastrated sheep, 10 Santa Ines, 10 $1 / 2$ Dorper x $1 / 2$ Santa Ines, and $103 / 4$ Dorper $x$ $1 / 4$ Santa Ines were used. The sheep were 82 days old average and $19.40 \mathrm{~kg}$ average initial weight. The diet used contained $169.0 \mathrm{~g} / \mathrm{kg}$ crude protein and $2.80 \mathrm{Mcal} / \mathrm{kg}$ DM. No effect of genotype was observed on the performance of lambs, except for the higher final body condition scores achieved by the Dorper crossbreds. The carcasses of the $1 / 2$ Dorper $x$ $1 / 2$ Santa Ines and $3 / 4$ Dorper $x \quad 1 / 4$ Santa Ines crossbreds lambs had greater rump and loin eye area and higher loin percentage compared to Santa Ines. Carcasses of $3 / 4$ Dorper x $1 / 4$ Santa Ines crossbreds lambs had greater chest and anterior width compared to Santa Ines and better carcass conformation and finish compared to other genotypes. Furthermore, the carcasses of Santa Ines and $1 / 2$ Dorper $x 1 / 2$ Santa Ines lambs had higher neck percentage compared to carcasses of $3 / 4$ Dorper $x 1 / 4$ Santa Ines.

Keywords: finishing, dry matter intake, crossbreds, weight gain, genotype 


\section{INTRODUÇÃO}

A ovinocultura no nordeste brasileiro vem se destacando como uma atividade promissora, entretanto, alguns entraves precisam ser vencidos para que esta atividade consiga alcançar maiores produtividades.

O sistema de produção de cordeiros com desmame tardio resulta em abate de animais com idade avançada, comprometendo a qualidade da carcaça e carne, como também aumenta o intervalo de partos das matrizes e a produtividade dos rebanhos. Segundo Fernandes et al. (2011) o desmame precoce de cordeiros é uma alternativa para aumentar a produtividade $\mathrm{e}$ proporcionar melhor recuperação da condição corporal das ovelhas.

De acordo com Pires et al. (2006) os cordeiros são a categoria ovina cuja carne tem maior aceitabilidade pelo mercado consumidor, haja vista suas melhores características de carcaça e carne. Portanto, uma alternativa interessante pode ser a redução na idade ao desmame que, além do aumento na produtividade atende as exigências dos consumidores.

Outras formas de intensificar a produção de carne ovina são a terminação em confinamento e o cruzamento entre raças, utilizando-se genótipos com aptidão para corte. Dessa forma, a redução na idade ao desmame dos cordeiros, bem como a terminação em confinamento permite a venda de animais precoces, fornecendo ao mercado carcaça e carne com qualidade superior. Segundo Ribeiro et al. (2009), o confinamento de cordeiros é estratégico, permitindo aumentar a taxa de desfrute, a produtividade e a rentabilidade, garantindo o fornecimento de carne ovina durante todo o ano
Dentre os genótipos mais utilizados para terminação em confinamento, destaca-se a raça Santa Inês que vem sendo utilizada ao longo do tempo por criadores nordestinos como genótipo único para produção de carne ovina. Por outro lado, outros produtores estão optando por utilizar no cruzamento como raça paterna a Dorper, especializada para corte, com fêmeas da raça Santa Inês e com matrizes mestiças Dorper x Santa Inês em cruzamento terminal. Portanto, é necessária uma avaliação dos genótipos mais utilizados nessa região, como raça Santa Inês e seus mestiços com Dorper, pois pouco se conhece dessas características.

Diante do exposto, objetivo desse estudo foi avaliar o desempenho $\mathrm{e}$ características de carcaça de cordeiros Santa Inês, $1 / 2$ Dorper x $1 / 2$ Santa Inês e $3 / 4$ Dorper x 1/4Santa Inês desmamados aos 75 dias de vida e terminados em confinamento.

\section{MATERIAL E MÉTODOS}

O experimento foi conduzido na Estação Experimental Benjamim Maranhão, pertencente à Empresa Estadual de Pesquisa Agropecuária da Paraíba (EMEPA-PB), localizada no município de Tacima-PB, altitude de $188 \mathrm{~m}$ e temperatura média de $24^{\circ} \mathrm{C}$.

Os cordeiros dessa pesquisa foram oriundos de cento e vinte ovelhas de um sistema de produção de ovinos de corte, sendo 80 matrizes da raça Santa Inês e $40 \frac{1}{2}$ Dorper $\times 1 / 2$ Santa Inês. As ovelhas Santa Inês foram dividas em dois grupos: 40 matrizes foram cruzadas com reprodutores da raça Santa Inês puros e 40 ovelhas foram cruzadas com reprodutores da raça Dorper puros. Por sua vez, as 40 matrizes $1 / 2$ Dorper $\times$ 
$1 / 2$ Santa Inês foram cruzadas com reprodutores Dorper puros.

Foram utilizados 30 cordeiros, sendo 10 da raça Santa Inês, $101 / 2$ Dorper $\times$ $1 / 2$ Santa Inês e $103 / 4$ Dorper $\times 1 / 4$ Santa Inês, que ficaram alojados em seis baias coletivas com capacidade para cinco animais por genótipo com acesso livre aos comedouros e bebedouros. A idade média e peso vivo médio dos cordeiros no início do experimento foram de 82 dias e 19,40 $\pm 3,13 \mathrm{~kg}$. Estes animais foram inicialmente vacinados contra clostridioses e vermifugados com aplicação subcutânea de ivermectina $1 \%$. $\mathrm{Na}$ fase de cria os cordeiros tiveram acesso ao cocho privativo (creep feeding) a partir dos 10 dias de vida até o desmame, recebendo uma dieta contendo 23,3\% de proteína bruta, 2,95 Mcal de EM/kg de MS, e $20,9 \%$ de fibra em detergente neutro, $4,80 \%$ de extrato etéreo e $6,15 \%$ de matéria mineral.

O desmame dos cordeiros ocorreu aos 75 dias de idade e durante o período de sete dias permaneceram alojados em baias coletivas objetivando reduzir o estresse pós-desmame. Após este período, os cordeiros destinados ao experimento foram selecionados levando-se em consideração a semelhança dos pesos vivos entre os genótipos.

O período experimental foi precedido de 14 dias para adaptação dos animais às instalações, alimentação e manejo. Como critério de abate, estabeleceu-se o período experimental de 40 dias de terminação. Foi utilizada dieta única fornecida duas vezes por dia às 7 e 15 horas, cuja composição alimentar e química estão apresentadas na Tabela 1.

Tabela 1. Composição alimentar e química da dieta experimental com base na matéria seca

\begin{tabular}{|c|c|}
\hline \multicolumn{2}{|l|}{ Composição alimentar } \\
\hline Silagem de sorgo $(\mathrm{g} / \mathrm{kg})$ & 300,0 \\
\hline Milho moído (g/kg) & 461,0 \\
\hline Farelo de soja $(\mathrm{g} / \mathrm{kg})$ & 213,0 \\
\hline Óleo de soja $(\mathrm{g} / \mathrm{kg})$ & 14,0 \\
\hline Sal mineral $(\mathrm{g} / \mathrm{kg})$ & 5,0 \\
\hline Calcário calcítico $(\mathrm{g} / \mathrm{kg})$ & 7,0 \\
\hline \multicolumn{2}{|l|}{ Composição química } \\
\hline Matéria seca $(\mathrm{g} / \mathrm{kg})$ & 544,7 \\
\hline Proteína bruta $(\mathrm{g} / \mathrm{kg})$ & 169,0 \\
\hline Energia metabolizável (Mcal/kg MS) & 2,80 \\
\hline Fibra em detergente neutro $(\mathrm{g} / \mathrm{kg})$ & 255,0 \\
\hline Nutrientes digestíveis totais $(\mathrm{g} / \mathrm{kg})$ & 778,0 \\
\hline Extrato etéreo (g/kg) & 48,3 \\
\hline Matéria mineral $(\mathrm{g} / \mathrm{kg})$ & 45,8 \\
\hline
\end{tabular}

A dieta foi formulada de acordo com o NRC (2007) para ganho de peso médio diário de $250 \mathrm{~g} / \mathrm{dia}$.

Estabeleceu-se um consumo de 5\% do peso vivo de matéria seca, sendo reajustado e pesado diariamente em função das sobras de $10 \%$ para posteriores cálculos dos consumos de matéria seca (CMS). Quando os animais atingiram o período de confinamento 
pré-estabelecido foram abatidos, sendo antes pesados, para cálculo do ganho de peso total (GPT), ganho de peso médio diário (GPMD) e conversão alimentar (CA).

A conversão alimentar foi obtida pela relação entre o consumo de matéria seca expresso em quilograma por dia e o ganho de peso médio diário também em quilograma por dia.

$\mathrm{O}$ consumo de água (CAG) foi determinado quantificando-se a oferta e sobra durante 48 horas, semanalmente, por o todo período experimental. Tal observação iniciava-se às $7 \mathrm{~h}$, momento que a água era ofertada em recipientes plásticos com capacidade para 10 litros, preenchidos com sete litros e meio. Após completar 24 horas, às $7 \mathrm{~h}$ do dia seguinte, a sobra era pesada para estimar o consumo diário, repetindo-se este procedimento por mais um período de 24 horas.

A avaliação do escore corporal foi feita no início e no final do experimento por três examinadores segundo a metodologia descrita por Cezar \& Sousa (2006). Para a atribuição dos escores foram feitas avaliações por meio de exame visual e palpação da região lombar e na inserção da cauda dos cordeiros, numa escala de 1 a 5 , com intervalos de 0,5 .

Para os procedimentos de abate os animais foram submetidos a um jejum alimentar por 16 horas. Posteriormente, foram pesados obtendo-se o peso vivo ao abate (PVA) e insensibilizados por concussão cerebral. Em seguida, foram suspensos pelas patas traseiras tendo seccionadas as veias jugulares $\mathrm{e}$ as artérias carótidas para sangria.

Após a sangria e esfola, foram retirados o conteúdo gastrintestinal, a pele, as vísceras, a cabeça, as patas e os órgãos genitais. Decorrido estes procedimentos, foi realizada a pesagem para obtenção do peso da carcaça quente (PCQ), e em seguida, as carcaças foram transportadas para uma câmara frigorífica a $4^{\circ} \mathrm{C}$, onde permaneceram por 24 horas.

Ao término do período de resfriamento, as carcaças dos cordeiros foram submetidas à avaliação de sua morfometria por meio das seguintes variáveis: largura do tórax, da garupa, do anterior, profundidade do tórax, perímetro da garupa, da perna $\mathrm{e}$ comprimento da carcaça.

Após a realização do exame morfométrico, foram determinadas as características qualitativas das carcaças em ambiente refrigerado, por meio de avaliações subjetivas da conformação e acabamento da carcaça e quantidade de gordura pélvico-renal. A avaliação da conformação da carcaça foi realizada com ênfase nas regiões anatômicas (perna, garupa, lombo, paleta e seus planos musculares) e o acabamento da carcaça com ênfase na espessura e distribuição dos planos adiposos em relação ao esqueleto, de acordo com as categorias e escores demonstrados por Cezar \& Sousa (2007), variando entre 1 (ruim para conformação e muito magro para acabamento) e 5 (excelente para conformação e muito gordo para acabamento). Ainda com a carcaça suspensa foi feita a determinação da quantidade da gordura pélvico-renal, de acordo com metodologia e escores (1 pouca e 3 muita), conforme descrita por Cezar \& Sousa (2007).

Realizou-se um corte transversal entre a $12^{\mathrm{a}}$ e $13^{\mathrm{a}}$ costelas na meia-carcaça esquerda, expondo a secção transversal do músculo Longissimus dorsi, na qual foi realizada a avaliação subjetiva da marmorização (1 inexistente e 5 excessivo), textura (1 muito fina e 5 muito grossa) e coloração da carne (1 rosa clara e 5 vermelho escuro), conforme Cezar \& Sousa (2007).

Decorrida a avaliação qualitativa da carcaça, procedeu-se a análise 
quantitativa da carcaça. Inicialmente, foi obtido o peso de corpo vazio (PCV) pela diferença entre o PVA e o peso do conteúdo gastrintestinal. Em seguida, as carcaças foram pesadas para obtenção do peso da carcaça fria (PCF). Posteriormente, foram determinados os rendimentos de carcaça quente (RCQ), de carcaça fria (RCF) e o rendimento biológico (RB), respectivamente pelas seguintes fórmulas: $\mathrm{RCQ}=(\mathrm{PCQ} / \mathrm{PVA})$ $\times 100, \mathrm{RCF}=(\mathrm{PCF} / \mathrm{PVA}) \times 100 \mathrm{e} \mathrm{RB}=$ $(\mathrm{PCQ} / \mathrm{PCV}) \times 100$. As perdas por resfriamento foram obtidas pela fórmula $(\mathrm{PPR} \%)=\mathrm{PCQ}-(\mathrm{PCF} / \mathrm{PCQ}) \times 100$.

Utilizando-se de uma película plástica transparente e de caneta apropriada foi captado e registrado o contorno da AOL para posterior determinação de sua área, por meio de mensuração, com régua, da largura máxima (A) e da profundidade máxima (B), de acordo com a fórmula: $\mathrm{AOL}=(\mathrm{A} / 2 * \mathrm{~B} / 2) \pi$. No mesmo corte, foi mensurada a espessura de gordura subcutânea (EGS) que foi medida com paquímetro digital e determinada pela profundidade da gordura na medida $\mathrm{C}$.

Posteriormente, a meia-carcaça direita foi seccionada em seis cortes comerciais descritos a seguir: pescoço: foi separado da carcaça em sua extremidade inferior entre a última vértebra cervical e a primeira torácica; paleta: foi obtida por secção da região axilar, pelo corte dos tecidos que unem a escápula e o úmero à região torácica da carcaça; lombo: foi obtido por meio de dois cortes, um entre a última vértebra torácica e a primeira lombar e outro entre a última lombar e a primeira sacral; costilhar: resultou de três cortes, o primeiro entre a última vértebra cervical e a primeira torácica, $\mathrm{o}$ segundo entre a última vértebra torácica e a primeira lombar e o terceiro em linha reta, iniciando-se na extremidade inferior do flanco/vazio e terminando na extremidade cranial do manúbrio do esterno; serrote: foi obtido por um único corte em linha reta que se inicia na extremidade inferior do flanco/vazio e termina na extremidade cranial do manúbrio do esterno; perna: foi separada da carcaça em sua extremidade superior, entre a última lombar e a primeira sacral. À medida que eram retirados da carcaça, os cortes eram imediatamente pesados.

Os dados das variáveis estudadas foram submetidos a uma análise de variância, obedecendo a um delineamento inteiramente casualizado com 10 repetições por tratamento, utilizando-se o teste $\mathrm{F}$ para comparação dos quadrados médios dos fatores testados.

O modelo estatístico utilizado foi o seguinte: $Y i j=\mu+G i+\varepsilon i j$, em que $Y i j$ $=$ valor observado da variável dependente estudada, $\mu=$ média geral; $\mathrm{Gi}=$ efeito do genótipo i; e $\varepsilon i j=$ erro aleatório associado a cada observação. As médias foram comparadas pelo teste Tukey a $5 \%$ de probabilidade.

\section{RESULTADOS E DISCUSSÃO}

Não houve efeito $(\mathrm{P}>0,05)$ do genótipo sobre os consumos de matéria seca (Tabela 2). Os cordeiros apresentaram consumos médios de matéria seca de $1,33 \mathrm{~kg} / \mathrm{dia}, 53,9 \mathrm{~g} / \mathrm{kg}$ do peso vivo e $120,07 \mathrm{~g} / \mathrm{kg}{ }^{0,75}$. Estes consumos foram superiores aos verificados por Sousa et al. (2012) que, estudaram cordeiros Santa Inês, F1 Dorper $\times$ Santa Inês e F1 Santa Inês $\times$ Sem Padrão Racial Definido e aos observados por Amaral et al. (2011) que, avaliaram cordeiros Santa Inês, $1 / 2$ Dorper $\times 1 / 2$ Santa Inês e $1 / 2$ White Dorper $\times 1 / 2$ Santa Inês. Vale salientar que, os trabalhos citados utilizaram na dieta como volumoso feno de gramíneas, e o presente estudo silagem de sorgo, portanto, apesar de ser um alimento aquoso os cordeiros 
desse trabalho apresentaram maiores consumos de matéria seca. Possivelmente a maior palatabilidade da silagem em relação ao feno tenha influenciado no maior consumo de matéria seca. Já o consumo de água em $\mathrm{kg} /$ dia foi maior $(\mathrm{P}<0,05)$ para os cordeiros $1 / 2$ Dorper $\times 1 / 2$ Santa Inês em relação aos Santa Inês. Provavelmente, o maior valor absoluto de consumo matéria de seca observado para os $1 / 2$ Dorper $\times 1 / 2$ Santa Inês com $1,40 \mathrm{~kg} / \mathrm{dia}$
$(\mathrm{P}=0,052)$ em relação à matéria seca consumida pelos cordeiros Santa Inês que foi de $1,25 \mathrm{~kg} /$ dia seja a explicação, tendo em vista que existe correlação alta e significativa entre os consumos de matéria seca e água. Segundo o NRC (2007), a relação entre consumo total de água e consumo de matéria seca é de 1,4 a 3 litros água/kg MS para ovinos. Os resultados obtidos no presente estudo estão de acordo com o referido manual.

Tabela 2. Pesos, consumos de matéria seca (CMS) e consumo de água (CAG) dos cordeiros, em função do genótipo

\begin{tabular}{|c|c|c|c|c|c|}
\hline \multirow{2}{*}{ Variável } & \multicolumn{3}{|c|}{ Genótipo } & \multirow{2}{*}{ CV $(\%)$} & \multirow{2}{*}{$\mathrm{P}$} \\
\hline & SI & $1 / 2 \mathrm{DP} \times 1 / 2 \mathrm{SI}$ & $3 / 4 \mathrm{DP} \times 1 / 4 \mathrm{SI}$ & & \\
\hline Peso inicial $(\mathrm{kg})$ & 18,80 & 19,38 & 20,04 & 16,48 & 0,690 \\
\hline Peso final $(\mathrm{kg})$ & 28,88 & 31,08 & 31,10 & 13,03 & 0,367 \\
\hline CMS (kg/dia) & 1,25 & 1,40 & 1,34 & 9,65 & 0,052 \\
\hline CMS (g/kg PV) & 53,10 & 55,60 & 53,00 & 12,88 & 0,653 \\
\hline $\operatorname{CMS}\left(\mathrm{g} / \mathrm{kg}^{0,75}\right)$ & 117,03 & 124,33 & 118,87 & 10,53 & 0,418 \\
\hline CAG (kg/dia) & $2,31^{\mathrm{b}}$ & $2,66^{\mathrm{a}}$ & $2,53^{\mathrm{ab}}$ & 11,02 & 0,030 \\
\hline CAG (g/kg PV) & 97,20 & 105,00 & 100,10 & 9,55 & 0,206 \\
\hline $\mathrm{CAG}\left(\mathrm{g} / \mathrm{kg}^{0,75}\right)$ & 214,40 & 235,04 & 224,33 & 7,97 & 0,051 \\
\hline CAG (kg/kg MS) & 1,84 & 1,92 & 1,88 & 12,59 & 0,781 \\
\hline
\end{tabular}

SI $=$ Santa Inês; $1 / 2 \mathrm{DP} \times 1 / 2 \mathrm{SI}=1 / 2$ Dorper $\times 1 / 2$ Santa Inês; $3 / 4 \mathrm{DP} \times 1 / 4 \mathrm{SI}=3 / 4$ Dorper $\times 1 / 4$ Santa Inês.

Médias seguidas por letras distintas diferem $(\mathrm{P}<0,05)$ entre si pelo teste Tukey.

O genótipo não influenciou $(\mathrm{P}>0,05)$ o ganho de peso total, ganho de peso médio diário e a conversão alimentar dos cordeiros (Tabela 3). A média do ganho de peso médio diário dos cordeiros foi de 273,6 g/dia, tendo os animais $1 / 2$ Dorper $\times 1 / 2$ Santa Inês obtido média de 292,5 g/dia ficando superior ao ganho estabelecido, que foi de $250 \mathrm{~g} /$ dia, entretanto, não foi observado diferença significativa entre os genótipos estudados.

Resultados semelhantes para o ganho de peso médio diário foram reportados por Araújo Filho et al. (2010) e por Sousa et al. (2012), que avaliaram o desempenho de cordeiros Santa Inês e mestiços de Dorper $\times$ Santa Inês. Diante dos resultados obtidos na literatura $\mathrm{e}$ também no presente estudo, a semelhança entre os genótipos Santa Inês e os mestiços de Dorper pode estar relacionada com o melhor acabamento de carcaça obtido pelos referidos animais, tendo em vista que se esperava que o cruzamento absorvente da raça Santa Inês pela Dorper aumentasse ganho de peso médio diário.

Estudos realizados por Cartaxo et al. (2008), verificaram que em cordeiros a demanda energética é bem maior para formação da gordura de cobertura e 
interna que para a formação de músculos. Assim, os mestiços de Dorper por terem apresentado melhor acabamento de carcaça que os Santa Inês demandaram maior energia da dieta para formação de tecido adiposo, e com isso não obtiveram maior ganho de peso médio diário justificando a similaridade para referida variável.

A conversão alimentar não diferiu $(\mathrm{P}>0,05)$ entre os genótipos avaliados.
Isto indica que os cordeiros apresentaram semelhança na transformação da matéria seca contida na dieta em peso corporal. Por outro lado, a justificativa para a conversão alimentar não ter sido diferente se deve ao fato do consumo de matéria seca expresso em $\mathrm{kg} /$ dia e ganho de peso médio diário não terem apresentado diferenças significativas.

Tabela 3. Ganho de peso total (GPT) e médio diário (GPMD), conversão alimentar (CA) e escore corporal inicial (ECI) e escore corporal final (ECF) dos cordeiros em função do genótipo

\begin{tabular}{|c|c|c|c|c|c|}
\hline \multirow{2}{*}{ Variável } & \multicolumn{3}{|c|}{ Genótipo } & \multirow{2}{*}{ CV (\%) } & \multirow{2}{*}{$\mathrm{P}$} \\
\hline & SI & $1 / 2 \mathrm{DP} \times 1 / 2 \mathrm{SI}$ & $3 / 4 \mathrm{DP} \times 1 / 4 \mathrm{SI}$ & & \\
\hline GPT (kg) & 10,08 & 11,70 & 11,06 & 14,60 & 0,092 \\
\hline GPMD (g/dia) & 252,00 & 292,50 & 276,50 & 14,62 & 0,090 \\
\hline $\mathrm{CA}(\mathrm{kg} / \mathrm{kg})$ & 5,10 & 4,81 & 5,02 & 18,17 & 0,762 \\
\hline ECI $(1-5)$ & $1,92^{\mathrm{b}}$ & $2,15^{\mathrm{ab}}$ & $2,42^{\mathrm{a}}$ & 12,28 & 0,001 \\
\hline ECF $(1-5)$ & $2,67^{b}$ & $3,20^{\mathrm{a}}$ & $3,42^{\mathrm{a}}$ & 9,54 & 0,001 \\
\hline
\end{tabular}

SI $=$ Santa Inês; $1 / 2$ DPx $1 / 2$ SI $=1 / 2$ Dorper $\times 1 / 2$ Santa Inês; 3/4DP $\times 1 / 4$ SI = 3/4Dorper $\times 1 / 4$ Santa Inês. Médias seguidas por letras distintas diferem $(\mathrm{P}<0,05)$ entre si pelo teste Tukey.

Nascimento et al. (2012) avaliando o consumo de nutrientes e características de carcaça de cordeiros Dorper $\times$ Sem Padrão Racial Definido, Santa Inês $\times$ Sem Padrão Racial Definido e Somalis $\times$ Sem Padrão Racial Definido também não encontraram diferença entre genótipo para conversão alimentar.

Os cordeiros Santa Inês e os 3/4Dorper x $1 / 4$ Santa Inês apresentaram escore corporal inicial e final diferentes $(\mathrm{P}<0,05)$, tendo os mestiços de Dorper obtidos resultados superiores aos cordeiros Santa Inês. Cartaxo \& Sousa (2008) encontraram correlação alta e significativa entre o escore corporal e a área de olho de olho, como também entre o escore corporal e espessura de gordura subcutânea, que são avaliações relacionadas com a conformação e acabamento de carcaça, respectivamente.
Provavelmente por este fato, é que os mestiços de Dorper tenham apresentado melhor conformação e acabamento de carcaça quando comparados com os Santa Inês.

Araújo Filho et al. (2010) avaliando o desempenho de cordeiros de diferentes genótipos também verificaram que os cordeiros mestiços Dorper $\times$ Santa Inês apresentaram escore corporal ao abate superior ao observado para os cordeiros da raça Santa Inês.

Houve efeito $(\mathrm{P}<0,05)$ do genótipo sobre a largura do tórax, da garupa e do anterior (Tabela 4). As carcaças dos cordeiros 3/4Dorper $\times 1 / 4$ Santa Inês apresentaram maiores $(\mathrm{P}<0,05)$ médias que as dos Santa Inês. As carcaças dos cordeiros $1 / 2$ Dorper $\times 1 / 2$ Santa Inês foram superiores $(\mathrm{P}<0,05)$ as dos Santa Inês para largura da garupa e obtiveram 
médias semelhantes aos demais genótipos para largura do tórax e do anterior.

Os cordeiros mestiços Dorper, independente da composição genética, apresentaram maior largura de garupa quando comparados com os animais Santa Inês, sugerindo um maior acúmulo de tecidos muscular e adiposo onde está localizado um dos cortes de primeira na carcaça ovina. Este resultado indica que o cruzamento entre a raça Dorper e a raça Santa Inês aumentou a quantidade dos referidos tecidos na região mais nobre da carcaça dos cordeiros, que é a garupa, sendo importante do ponto de vista comercial.

Tabela 4. Características morfométricas de carcaça dos cordeiros em função do genótipo

\begin{tabular}{|c|c|c|c|c|c|}
\hline \multirow{2}{*}{ Variável } & \multicolumn{3}{|c|}{ Genótipo } & \multirow{2}{*}{$\mathrm{CV}(\%)$} & \multirow{2}{*}{$\mathrm{P}$} \\
\hline & SI & $1 / 2 \mathrm{DP} \times 1 / 2 \mathrm{SI}$ & $3 / 4 \mathrm{DP} \times 1 / 4 \mathrm{SI}$ & & \\
\hline Largura do tórax & $17,84^{b}$ & $18,76^{\mathrm{ab}}$ & $19,83^{\mathrm{a}}$ & 8,70 & 0,045 \\
\hline Largura da garupa & $17,91^{\mathrm{b}}$ & $19,38^{\mathrm{a}}$ & $19,37^{\mathrm{a}}$ & 5,32 & 0,004 \\
\hline Profundidade do tórax & 22,93 & 23,17 & 23,18 & 4,99 & 0,873 \\
\hline Largura do anterior & $13,55^{\mathrm{b}}$ & $14,43^{\mathrm{ab}}$ & $15,12^{\mathrm{a}}$ & 7,93 & 0,021 \\
\hline Perímetro da garupa & 55,77 & 58,78 & 58,80 & 5,79 & 0,101 \\
\hline Perímetro da perna & 36,14 & 36,81 & 37,70 & 6,41 & 0,368 \\
\hline Comprimento da carcaça & 56,85 & 55,82 & 54,59 & 6,30 & 0,384 \\
\hline
\end{tabular}

SI = Santa Inês; $1 / 2 \mathrm{DP} \times 1 / 2 \mathrm{SI}=1 / 2$ Dorper $\times 1 / 2$ Santa Inês; $3 / 4 \mathrm{DP} \times 1 / 4 \mathrm{SI}=3 / 4$ Dorper $\times 1 / 4$ Santa Inês.

Médias seguidas por letras distintas diferem $(\mathrm{P}<0,05)$ entre si pelo teste Tukey.

As carcaças dos cordeiros mestiços Dorper obtiveram melhor $(\mathrm{P}<0,05)$ conformação e acabamento quando comparadas com as carcaças dos cordeiros Santa Inês (Tabela 5). As carcaças dos cordeiros 3/4Dorper $\times$ $1 / 4$ Santa Inês foram superiores as carcaças dos demais genótipos. Já as carcaças dos cordeiros $1 / 2$ Dorper $\times$ $1 / 2$ Santa Inês apresentaram melhor conformação e acabamento do que as carcaças dos cordeiros Santa Inês. Isto sugere que o cruzamento absorvente da raça Santa Inês pela Dorper pode melhorar gradativamente as referidas características e proporcionar ao mercado carcaças com maior quantidade e melhor distribuição de musculosidade e adiposidade e, por conseguinte, carne com melhor qualidade sensorial. Esta afirmativa vem corroborar com Sañudo et al.
(1997), afirmando que a utilização de raças especializada para produção de carne influenciam as características da carcaça de cordeiros, principalmente o acabamento e as características qualitativas da carne.

Resultados semelhantes foram reportados por Costa et al. (2010) que avaliaram as características de carcaça de cordeiros Morada Nova, Santa Inês e Dorper $\times$ Santa Inês e por Cartaxo et al. (2011) que estudaram as mesmas características em cordeiros Santa Inês, Santa Inês $\times$ Sem Padrão Racial Definido e Dorper $\times$ Santa Inês, tendo ambos os trabalhos verificado que as carcaças dos mestiços Dorper $\times$ Santa Inês apresentaram melhor conformação e acabamento.

Para as demais características qualitativas de carcaça não foi observada diferenças $(\mathrm{P}>0,05)$ entre 
genótipos. Segundo Cezar \& Sousa (2007), o principal fator que diferencia a textura, o marmoreio e a coloração da carne na carcaça, é a idade do animal, neste ponto os cordeiros do presente estudo eram contemporâneos, com aproximadamente 4,5 meses de idade no momento do abate, provavelmente por este fato, não se tenha verificado diferenças.

Tabela 5. Características qualitativas de carcaça dos cordeiros em função do genótipo

\begin{tabular}{lccccc}
\hline Variável & \multicolumn{3}{c}{ Genótipo } & CV $(\%)$ & $\mathrm{P}$ \\
\cline { 2 - 4 } & $\mathrm{SI}$ & $1 / 2 \mathrm{DP} \times 1 / 2 \mathrm{SI}$ & $3 / 4 \mathrm{DP} \times 1 / 4 \mathrm{SI}$ & & \\
\hline Conformação & $2,50 \mathrm{c}$ & $3,19 \mathrm{~b}$ & $3,64 \mathrm{a}$ & 7,19 & 0,0001 \\
Acabamento & $2,65 \mathrm{c}$ & $3,06 \mathrm{~b}$ & $3,65 \mathrm{a}$ & 11,29 & 0,0001 \\
Gordura pélvico-renal & 2,05 & 2,11 & 2,28 & 28,05 & 0,679 \\
Textura & 3,15 & 3,99 & 3,57 & 33,91 & 0,315 \\
Marmoreio & 0,77 & 0,90 & 0,91 & 53,56 & 0,752 \\
Cor & 3,00 & 3,86 & 3,52 & 33,62 & 0,267 \\
\hline
\end{tabular}

SI = Santa Inês; $1 / 2 \mathrm{DP} \times 1 / 2 \mathrm{SI}=1 / 2$ Dorper $x 1 / 2$ Santa Inês; $3 / 4 \mathrm{DP} \times 1 / 4 \mathrm{SI}=3 / 4$ Dorper $\times 1 / 4$ Santa Inês.

Médias seguidas por letras distintas diferem $(\mathrm{P}<0,05)$ entre si pelo teste Tukey.

Não houve efeito $(\mathrm{P}>0,05)$ do genótipo sobre os pesos e rendimentos de carcaça (Tabela 6). Os cordeiros apresentaram pesos médios de carcaça quente e fria de $14,71 \mathrm{~kg}$ e $14,57 \mathrm{~kg}$, respectivamente. Os rendimentos médios de carcaça quente, de carcaça fria e biológico foram de $50,80 \%, 50,30 \%$ e $59,55 \%$, na mesma ordem. Estes rendimentos de carcaça podem ser considerados bons, devendo ser atribuído ao peso médio ao abate dos cordeiros que foi de $30,35 \mathrm{~kg}$. Sabe-se que existe uma correlação alta e significativa entre o peso vivo ao abate e os rendimentos de carcaça. Cartaxo \& Sousa (2008) encontraram correlação alta e significativa $(\mathrm{P}<0,001) \quad$ com coeficiente de 0,81 entre o peso de carcaça quente e o rendimento de carcaça quente.

Da mesma forma da presente pesquisa, Ribeiro et al. (2009) não encontraram diferença para o rendimento de carcaça quente entre os três genótipos estudados.

Rendimentos de carcaça inferiores aos encontrados no presente estudo foram reportados por Furusho Garcia et al. (2010) que avaliaram as características de carcaça de cordeiros Santa Inês puros, Dorper $\times$ Santa Inês e Texel $\times$ Santa Inês submetidos a diferentes sistemas de manejo. Estes autores verificaram que para os animais submetidos ao manejo intensivo os rendimentos médios de carcaça quente, de carcaça fria $\mathrm{e}$ biológico foram de 47,81\%, 46,17\% e $53,13 \%$, respectivamente.

$\mathrm{O}$ genótipo não influenciou $(\mathrm{P}>0,05)$ as perdas por resfriamento e a espessura de gordura subcutânea dos cordeiros. As perdas por resfriamento com média de $0,97 \%$ foram baixas, tendo em vista que a espessura de gordura subcutânea média foi de $1,25 \mathrm{~mm}$. Contudo, as carcaças dos cordeiros 3/4Dorper $\times$ $1 / 4$ Santa Inês obtiveram espessura de gordura subcutânea $27 \%$ maior que $1 / 2$ Dorper $\times 1 / 2$ Santa Inês e $29 \%$ maior que os Santa Inês. Vale salientar que este tecido adiposo de cobertura age como isolante térmico das carcaças, reduzindo as perdas por resfriamento. 
Tabela 6. Pesos de carcaça quente (PCQ) e fria (PCF), rendimentos de carcaça quente (RCQ), de carcaça fria (RCF), biológico (RB), perdas por resfriamento (PPR), espessura de gordura subcutânea (EGS) e área de olho de lombo (AOL) em função do genótipo

\begin{tabular}{|c|c|c|c|c|c|}
\hline \multirow{2}{*}{ Variável } & \multicolumn{3}{|c|}{ Genótipo } & \multirow{2}{*}{ CV (\%) } & \multirow{2}{*}{$\mathrm{P}$} \\
\hline & SI & $1 / 2 \mathrm{DP} \times 1 / 2 \mathrm{SI}$ & $3 / 4 \mathrm{DP} \times 1 / 4 \mathrm{SI}$ & & \\
\hline PCQ (kg) & 13,82 & 14,99 & 15,34 & 15,03 & 0,290 \\
\hline PCF (kg) & 13,73 & 14,81 & 15,18 & 15,15 & 0,327 \\
\hline RCQ (\%) & 50,68 & 50,58 & 51,15 & 3,72 & 0,772 \\
\hline $\mathrm{RCF}(\%)$ & 50,32 & 49,97 & 50,62 & 3,71 & 0.739 \\
\hline RB (\%) & 59,47 & 58,93 & 60,27 & 2,98 & 0,255 \\
\hline PPR (\%) & 0,70 & 1,20 & 1,03 & 74,44 & 0,309 \\
\hline EGS (mm) & 1,10 & 1,13 & 1,54 & 62,65 & 0,391 \\
\hline $\operatorname{AOL}\left(\mathrm{cm}^{2}\right)$ & $12,43^{\mathrm{b}}$ & $14,28^{\mathrm{a}}$ & $14,02^{\mathrm{a}}$ & 11,86 & 0,048 \\
\hline
\end{tabular}

$\mathrm{SI}=$ Santa Inês; $1 / 2 \mathrm{DP} \times 1 / 2 \mathrm{SI}=1 / 2$ Dorper $\times 1 / 2$ Santa Inês; $3 / 4 \mathrm{DP} \times 1 / 4 \mathrm{SI}=3 / 4$ Dorper $\times 1 / 4$ Santa Inês.

Médias seguidas por letras distintas diferem $(\mathrm{P}<0,05)$ entre si pelo teste Tukey.

Diferentemente do presente estudo, Rhee et al. (2003) e Gutiérrez et al. (2005) com cordeiros terminados em confinamento encontraram diferença entre genótipos para espessura de gordura subcutânea. Da mesma forma, Khaldari et al. (2007) avaliaram dois grupos de cordeiros separadamente e verificaram que os cordeiros puros apresentaram menor espessura de gordura subcutânea.

As carcaças dos cordeiros mestiços Dorper apresentaram maior $(\mathrm{P}<0,05)$ área de olho de lombo quando comparadas com as carcaças dos cordeiros Santa Inês. As carcaças dos cordeiros 3/4Dorper $\times 1 / 4$ Santa Inês apresentaram $14,02 \mathrm{~cm}^{2}$, as dos $1 / 2$ Dorper $\times \quad 1 / 2$ Santa Inês $14,28 \mathrm{~cm}^{2}$, sendo superiores aos $12,43 \mathrm{~cm}^{2}$ observados para as carcaças dos Santa Inês. Resultado semelhante foi observado por Costa et al. (2010), que observaram maior área de olho de lombo para os cordeiros Dorper $\times$ Santa Inês em comparação Santa Inês.

A área de olho de lombo é um indicativo de músculo na carcaça, pressupõe-se que o cruzamento da raça Dorper com a Santa Inês melhora o índice de musculosidade das carcaças. Alguns pesquisadores também observaram diferenças entre genótipos para área de olho de lombo (BURKE et al., 2003; ALMEIDA et al., 2006; BURKE et al., 2007).

As carcaças dos cordeiros mestiços de Dorper apresentaram o maior $(\mathrm{P}<0,05)$ percentual de lombo quando comparados com os Santa Inês (Tabela 7). Este resultado pode ser justificado pelo maior escore corporal final obtido por esses animais (Tabela 3). Cartaxo et al. (2011) avaliando cordeiros Santa Inês, Santa Inês $\times$ Sem Padrão Racial Definido e Dorper $\times$ Santa Inês, também verificaram que os mestiços Dorper alcançaram maior percentual de lombo quando comparados com Santa Inês e seus mestiços. Segundo os referidos autores, o lombo comercializado na forma de bistecas apresenta um valor diferenciado, sendo economicamente vantajoso este maior percentual.

O percentual de paleta $(17,13 \%)$ foi maior $(\mathrm{P}<0,05)$ para os cordeiros Santa Inês em relação aos mestiços Dorper. Cezar (2004) avaliou cordeiros Santa Inês e F1 Dorper $\times$ Santa Inês também observou que os Santa Inês apresentaram maior proporção deste corte. 
Rev. Bras. Saúde Prod. Anim., Salvador, v.18, n.2, p.388-401 abr./jun., 2017

Tabela 7. Rendimentos dos cortes comerciais da carcaça dos ovinos, em função do genótipo

\begin{tabular}{|c|c|c|c|c|c|}
\hline \multirow{2}{*}{ Variável } & \multicolumn{3}{|c|}{ Genótipo } & \multirow{2}{*}{ CV (\%) } & \multirow{2}{*}{$\mathrm{P}$} \\
\hline & SI & $1 / 2 \mathrm{DP} \times 1 / 2 \mathrm{SI}$ & $3 / 4 \mathrm{DP} \times 1 / 4 \mathrm{SI}$ & & \\
\hline Perna (\%) & 29,42 & 29,99 & 29,82 & 7,91 & 0,877 \\
\hline Lombo (\%) & $10,62^{\mathrm{b}}$ & $12,23^{\mathrm{a}}$ & $12,21^{\mathrm{a}}$ & 5,60 & 0,001 \\
\hline Paleta (\%) & $17,13^{\mathrm{a}}$ & $16,13^{b}$ & $15,76^{\mathrm{b}}$ & 4,08 & 0,001 \\
\hline Costilhar (\%) & 3,29 & 3,66 & 3,64 & 15,45 & 0,331 \\
\hline Serrote $(\%)$ & 5,64 & 5,33 & 5,49 & 10,25 & 0,540 \\
\hline Pescoço (\%) & $7,07^{\mathrm{a}}$ & $7,08^{\mathrm{a}}$ & $5,85^{\mathrm{b}}$ & 12,28 & 0,007 \\
\hline
\end{tabular}

SI = Santa Inês; $1 / 2 \mathrm{DP} \times 1 / 2 \mathrm{SI}=1 / 2$ Dorper $\times 1 / 2$ Santa Inês; $3 / 4 \mathrm{DP} \times 1 / 4 \mathrm{SI}=3 / 4$ Dorper $\times 1 / 4$ Santa Inês.

Médias seguidas por letras distintas diferem $(\mathrm{P}<0,05)$ entre si pelo teste Tukey.

Provavelmente, os animais Santa Inês por serem originários de região semiárida, com grande escassez alimentar, apresentam proporcionalmente maiores membros para facilitar a busca por forragem, enquanto os mestiços de Dorper, por serem $1 / 2$ e $3 / 4$ de raça especializada para corte, herdaram membros mais curtos em virtude da conformação corporal mais compactada alcançada pelos animais Dorper por meio do melhoramento genético a que foram submetidos. Assim, a paleta dos mestiços de Dorper foi relativamente menor do que a dos animais Santa Inês.

As carcaças dos cordeiros Santa Inês e $1 / 2$ Dorper $\times 1 / 2$ Santa Inês apresentaram maior percentual de pescoço com 7,07 e $7,08 \%$, respectivamente, quando comparados com os $3 / 4$ Dorper $\times 1 / 4$ Santa Inês que obtiveram 5,85\%. Araújo Filho et al. (2010) também não encontraram diferença entre os cordeiros Santa Inês e $1 / 2$ Dorper $\times 1 / 2$ Santa Inês para 0 percentual de pescoço. De acordo com Furusho-Garcia et al. (2003), este maior percentual é desvantajoso, tendo em vista que o pescoço não é um corte de primeira.

Animais de raças especializadas para corte, normalmente apresentam as extremidades corporais, pescoço e membros, mais curtos, haja vista que o melhoramento genético dessas raças seleciona sempre animais de conformação corporal mais compacta, ou seja, com altura e comprimento corporais menores em relação a sua profundidade corporal, buscando assim maior percentual do tronco em detrimento as extremidades corporais, uma vez que a maior proporção da carcaça vem do tronco e não de regiões apendiculares do corpo animal. Provavelmente, isso tenha concorrido para que os mestiços com maior proporção genética, os mestiços $3 / 4$ Dorper, tenham apresentado menor proporção de pescoço.

Para os demais cortes comerciais não foram observadas diferenças $(\mathrm{P}>0,05)$. Diferentemente, Pérez et al. (2007) ao avaliarem cordeiros Suffolk, Merino, Suffolk $\times$ Merino e Suffolk $\times$ Corrriedale observaram diferença entre genótipo para proporção de perna.

A utilização de reprodutores da raça Dorper cruzados com ovelhas $1 / 2$ Dorper $\times 1 / 2$ Santa Inês propicia cordeiros com maior escore corporal no início e no final da terminação em confinamento, como também carcaças com melhor acabamento e conformação. As carcaças dos cordeiros mestiços Dorper apresentam maior largura da garupa, musculosidade, evidenciada pela área de olho de lombo, e percentual de lombo. Por outro lado, as carcaças dos 
cordeiros Santa Inês e $1 / 2$ Dorper $\times$ $1 / 2$ Santa Inês apresentaram maior percentual de pescoço.

\section{REFERÊNCIAS}

ALMEIDA, H.S.L.; PIRES, C.C.; GALVANI, D.B.; LIMA, R.F. de; HASTENPFLUG, M.; GASPERIN, B.G. Características de carcaça de cordeiros Ideal e cruzas Border Leicester X Ideal submetidos a três sistemas alimentares. Ciência Rural, v.36, n.5, p.1546-1552, 2006.

AMARAL, R.M.; MACEDO, F.A.F.; ALCALDE, C.G.; LINO, D.A.; BÁNKUTI, F.I.; MACEDO, F.G. de; DIAS, F.B.; GUALDA, T.P. Desempenho produtivo e econômico de cordeiros confinados abatidos com três espessuras de gordura. Revista Brasileira de Saúde e Produção Animal [online], v.12, n.1, p.155-165, 2011.

ARAÚJO FILHO, J.T.; COSTA, R.G.; FRAGA, A.B.; SOUSA, W.H. de; CEZAR, M.F.; BATISTA, A.S.M. Desempenho e composição da carcaça de cordeiros deslanados terminados em confinamento com diferentes dietas.

Revista Brasileira de Zootecnia, v.39, p.363-371, 2010.

BURKE, J.M.; APPLE, J.K.; ROBERTS, W.J.; BOGER, CB, KEGLEY, EB. Effect of breed-type on performance and carcass traits of intensively managed hair sheep. Meat Science, n.63, p.309-315, 2003.

BURKE, J.M.; APPLE, J.K. Growth performance and carcass traits of forage-fed hair sheep wethers. Small Ruminant Research, v.67, p.264-270, 2007.
CARTAXO, F.Q.; SOUSA, W.H.; CEZAR, M.F.; GONZAGA NETO, S.; CUNHA, M. das G.G. Efeitos do genótipo e da condição corporal sobre o desempenho de cordeiros terminados em confinamento. Revista Brasileira de Zootecnia, v.37, p.1483-1489, 2008.

CARTAXO, F.Q.; SOUSA, W.H. Correlações entre as características obtidas in vivo por ultra-som e as obtidas na carcaça de cordeiros terminados em confinamento. Revista Brasileira de Zootecnia, v.37, n.8, p.1490-1495, 2008.

CARTAXO, F.Q., SOUSA, W.H., COSTA, R.G.; CEZAR, M.F.; PEREIRA FILHO, J.M.; CUNHA, M. das G.G..

Características quantitativas da carcaça de cordeiros de diferentes genótipos submetidos a duas dietas. Revista Brasileira de Zootecnia, v.40, p.22202227, 2011.

CEZAR, M.F. Características de carcaça e adaptabilidade fisiológica de ovinos durante a fase de cria. 2004. $88 \mathrm{f}$. Tese (Doutorado em Zootecnia) Universidade Federal da Paraiba, Areia.

CEZAR, M.F.; SOUSA, W.H. Avaliação e utilização da condição corporal como ferramenta de melhoria da reprodução e produção de ovinos e caprinos de corte. Revista Brasileira de Zootecnia, v.35, p.541-565, 2006.

CEZAR, M.F.; SOUSA, W.H. Carcaças ovinas e caprinas: obtenção, avaliação e classificação. Uberaba: Agropecuária Tropical, 2007. 232p.

COSTA, R.G.; ARAÚJO FILHO, J.T.; SOUSA, W.H.; GONZAGA NETO, S.; MADRUGA, M.S.; FRAGA, A.B. Effect of diet and genotype on carcass characteristics of feedlot hair sheep.

Revista Brasileira de Zootecnia, v.39, n.12, p.2763-2768. 2010. 
FERNANDES, S.R.; MONTEIRO, A.L.G.; SILVA, C.J.A.; SILVA M.G.B. da; ROSSI JÚNIOR, P.; SOUZA, D.F. de; SALGADO, J.A.; HENTZ, F. Desmame precoce e a suplementação concentrada no peso ao abate e nas características de carcaça de cordeiros terminados em pastagem. Revista Brasileira de Saúde e Produção Animal [online], v.12, n.2, p.527-537, 2011.

FURUSHO-GARCIA, I.F.; PEREZ, J.R.O.; TEIXEIRA, J.C. Componentes de carcaça e composição de alguns cortes de cordeiros Texel x Bergamácia, Texel x Santa Inês e Santa Inês puros, terminados em confinamento, com casca de café como parte da dieta. Revista Brasileira de Zootecnia, v.32, n.6, p.1999-2006, 2003. (supl. 2).

FURUSHO-GARCIA, I.F.; COSTA, T.I.R.; ALMEIDA, A.K.; PEREIRA, I.G.; ALVARENGA, F.A.P.; LINS LIMA, N.L. Performance and carcass characteristics of Santa Inês pure lambs and crosses with Dorper e Texel at different management systems. Revista Brasileira de Zootecnia, v.39, p.13131321, 2010.

GUTIÉRREZ, J; RUBIO, M.S.; MÉNDEZ, R.D. Effects of crossbreeding Mexican Pelibuey sheep with Rambouillet and Suffolk on carcass traits. Meat Science, v.70, p.1$5,2005$.

KHALDARI, M.; KASHAN, N.E.J.; AFZALZADEH, A.; SALEHI, A.

Growth and carcass characteristics of crossbred progeny from lean-tailed and fat-tailed sheep breeds. South African Journal of Animal Science, v.37, n.1, p.51-56, 2007.
NASCIMENTO, E.N.; ROGÉRIO, M.C.P.;BATISTA, A.S.M.. Nutrient intake and quantitative aspects of carcass of finishing sheep fed with diets containing cashew nut meal, Revista Brasileira de Saúde e Produção Animal [online], v.13, n.4, p.1099-1111, 2012.

NATIONAL RESEARCH COUNCIL NRC. Nutrient Requirements of Small Ruminants: Sheep, Goats, Cervids, and New World Camelids. 1.ed.

Washington, D.C.: National Academy Press, 2007. 384p.

RHEE, K.S.; LUPTON, C.J.; Y.A. ZIPRIN, YA.; RHEE, K.C. Carcass traits of Rambouillet and Merino $\times$

Rambouillet lambs and fatty acid profiles of muscle and subcutaneous adipose tissues as affected by new sheep production system. Meat Science, n.65, p.693-699, 2003.

RIBEIRO, E.L.A.; OLIVEIRA, H.C.; CASTRO, F.A.B.; MIZUBUTI, I.Y.; SILVA, L. das D.F. da; M.A.A. de F. Desempenho em confinamento e componentes do peso vivo de cordeiros mestiços de três grupos genéticos.

Ciência Rural, v.39, n.7, p.2162-2168, 2009.

SAÑUDO, C.; CAMPO, M.M.; SIERRA, I.; MARÍA, G.A.;. OLLETA, J.L.; SANTOLARIA, P. Breed effect on carcass and meat quality of suckling lambs. Meat Science, v.46, n.4, p.357365, 1997.

SOUSA, W.H.; CARTAXO, F.Q.; COSTA, R.G.; CEZAR, M.F.; CUNHA, M. das G.G.; PEREIRA FILHO, J.M.; NEUBE SANTOS, N.M. dos. Biological and economic performance of feedlot lambs feeding on diets with different energy densities. Revista Brasileira de Zootecnia, v.41, p.1285-1291, 2012. 
PÉREZ, P.; MAINO, M.; MORALES, M.S.; KÖBRICH, C.; BARDON, C.;

POKNIAK, J. Gender and slaughter weight effects on carcass quality traits of suckling lambs from four different genotypes. Small Ruminant Research, n.70, p.124-130, 2007.

PIRES, C.C.; GALVANI, D.B.;

CARVALHO, S.; CARDOSO, A.R.; GASPERIN, B.G. Características da carcaça de cordeiros alimentados com dietas contendo diferentes níveis de fibra em detergente neutro. Revista Brasileira de Zootecnia, v.35, n.5, p.2058-2065, 2006.

Data de recebimento: 10/03/2017

Data de aprovação: 22/05/2017 